\title{
Learning Style Instruments: Implications of Content
}

\author{
Alzain Meftah Alzain, Gren Ireson, Steve Clark, Ali Jwaid \\ Nottingham Trent University \\ United Kingdom
}

\begin{abstract}
Research into the use of information technology in computing-based education has indicated that students have different abilities, needs and learn in different ways. Following a review of learning styles. This study depends on new learning style instrument, which was constructed using Visual and Active forms of information such as figures, charts and equations rather than depending only on textual information. In a sample of six Masters Students, the learning style of participants was measured twice, once by the VARK questionnaire and once by the developed instrument, which uses both visual and active forms of information. The results of both approaches were compared and an interview with each participant has been conducted to further investigate the outcomes. The results of this study showed that there were significant differences among student preferences of learning. They also revealed that using visual and active content for constructing the learning style instruments has a significant effect on the measured preferred learning style of students.
\end{abstract}

\section{Introduction}

Instruments of learning style are built on the premise that there is no one teaching style or curriculum that fits all learners [1-3] because they have different preferences, needs and abilities. Therefore, to improve both achievement and engagement of students, the differences amongst students need to be considered in our teaching. Numerous studies show that if the teaching environment is matched the student preferred learning style, learning will be better, easier and faster and achievement of students will be increased [2-5].

Table 1 shows a number of well-known learning style models and instruments, which could be used to detect the preferred learning style of students $[1,6$, 7]. Existing learning style instruments have typically been constructed using only textual information which is more suitable for verbal learners than others. For instance, there are no visual or active forms of information in the instruments. Thus, there may be differences in how students interact with the items of the instrument, resulting in threatening the suitability, validity and reliability of measurement.

This paper aims to investigate the implications of using visual and active forms of information in the construction of the instruments that are used to measure the learning style. As a result, the visual and active students are expected to respond strongly to these forms of information, because it is more suitable for them. Accordingly, this may affect the accuracy of detection their learning style.

Table 1. Learning Style Models

\begin{tabular}{|l|l|}
\hline \multicolumn{1}{|c|}{ Model } & \multicolumn{1}{c|}{ Instrument } \\
\hline VARK & VARK Questionnaire \\
\hline $\begin{array}{l}\text { Felder- } \\
\text { Silverman }\end{array}$ & Index of Learning Style (ILS) \\
\hline Gregorc & Gregorc Style Delineator (GSD) \\
\hline Kolb & Learning Style I inventory (LSI) \\
\hline Dunn-Dunn & $\begin{array}{l}\text { Productivity Environmental Preference } \\
\text { (PEPS) }\end{array}$ \\
\hline
\end{tabular}

\section{Assumptions of study}

Over the last few decades, a number of learning style instruments have been developed to help people know their preferred way to learn [6]. The literature review revealed that none of the current learning style instruments present information in different styles. And the content of these instruments depends only on the textual form of information and this might be leading to a bias in measuring of learning style because the textual information is more suitable for verbal students than others. Although these instruments have seen a significant amount of statistical research in terms of reliability and validity, unfortunately in terms of investigating the impact of the content type this work is still in its infancy. Accordingly, the researchers claim that the instrument itself should, therefore, also contain different forms of information. Since it is not known to what extent visual and active content of an instrument impacts on learning style measurement, more research is needed in this area.

\section{Literature Review}

Within the last four decades, a number of learning style models and instruments have emerged to help learners to know more about how they prefer to learn. Although all of these instruments have been designed based on the same premise, which is learners respond and interact differently to the different forms of information; these models have different views as to the characteristics that should 
be adopted under the umbrella of learning styles [8, 9].

\subsection{Previous learning style models}

In this paper, five well-known learning style models and their instruments are investigated for comparison purposes.

3.1.1. VARK learning style model. The VARK (Visual, Aural, Read and Write, Kinesthetic) Model was extended from VAK model by Neil Fleming in 2006 [10]. Fleming introduces the learning style as "an individual's characteristics and preferred ways of gathering, organizing, and thinking about information" [11]. Therefore, VARK is a sensory model focused on the manner in which learners prefer to receive and deliver new knowledge.

Based on the VARK model, learners could be classified into [6, 10]:

- Visual: visual students respond strongly to visual resources, including charts, pictures, diagrams, maps, flow charts and highlighted text. They also prefer to draw maps or charts to deliver information to others.

- Aural: aural students get more from listening, discussion, chatting and records. They also prefer to talk to others and discuss with them to explain facts.

- Read and Write: These learners seem to be more comfortable with written resources. So, they prefer textbooks and lecture notes.

- Kinesthetic: Kinesthetic students tend to use practical resources such as exercises and case studies. They also prefer doing things to get information about it.

The VARK Questionnaire is available at (www.vark-learn.com), it includes sixteen questions, for each question, there are four answers which correspond to the tendencies in VARK Model (Visual, Verbal, Read/Write and Kinesthetic) and the participant is to select one answer or more which translates to his/her perception. Questions that do not apply could be ignored.

3.1.2. Felder-Silverman learning and teaching model. The Felder-Silverman Learning and Teaching Style Model was developed by Felder and Silverman in 1988 and appears to be more applicable to the context of engineering education. It also proposes classifying teaching methods according to learning style poles by providing a parallel teaching style [12]. Hawk and Shah [6] mention that this model defines the learning style as "the characteristic strengths and preferences in the ways individuals take in and process information".

Based on this Model, learners could be classified as follows $[4,12]$ :
- Sensing: Sensors get more from facts and experimentation and they are more comfortable with detailed data.

- Intuitive: they respond strongly to theories, symbols, less detailed data and they are less patient with timed tests.

- Visual: Visual learners prefer sight in receiving new information. Therefore, they get more from pictures, figures, charts... etc.

- Verbal: Verbal learners prefer to receive new information verbally. Therefore, they get more from the discussion, records, chatting and reading.

- Active: Active learners get more from practical lessons and they also prefer to work in groups.

- Reflective: Reflective learners get more from theoretical lessons and they also prefer to work individually.

- Sequential: They prefer to learn in a sequential manner according to logically consecutive steps and they also prefer tackling the complexity in a steady progress.

- Global: Global learners usually do not depend on the clear sequence in progressing because they are able to link and integrate the ideas to form overall concepts.

The Index of Learning Style (ILS) is a webbased instrument available at (www.ncsu.edu/felderpublic/ILSpage.html) this questionnaire contains 44 questions covering the four basic dimensions of the model. Each of the 11 questions, provide metrics for only one dimension and participants choose only one answer for each question.

3.1.3. Kolb experiential theory. The Kolb Experiential Learning Theory addresses experience as a source of learning and development. This theory considers learning as creating new knowledge through the transformation of experience and defines the learning style as "generalized differences in learning orientation based on the degree to which people emphasize the four modes of the learning process" [13].

Kolb represents the learning process in a cycle consisting of four modes. This cycle usually starts with Experience (CE), and respectively moves to Reflective Observation (RO), Abstract Conceptualization (AC) and Active Experimentation (AE).

According to the Kolb model, there are four learning styles resulting from combining the preferences of adjacent poles in the experiential learning cycle [6], thus learners could be classified as follows $[6,13]$ :

- Divergers (combination of Concrete Experience (CE) and Reflective Observation (RO)): learners with this preference seem to be more 
imaginative, emotional and they prefer to work in groups.

- Assimilators (combination of Abstract Conceptualization (AC) and Reflective Observation (RO)): They have the ability to deal with a wide range of information, rearrange it logically and they seem to be more inductive.

- Convergers (combination of Abstract Conceptualization (AC) and Active Experimentation (AE)): Convergers learning preference is more active, they get more from technical and practical tasks.

- Accommodators (combination of Concrete Experience (CE) and Active Experimentation (AE)): Learners with this style usually depend on others to get information and tend to adopt an intuitive approach to solving problems rather than logical analysis.

The Learning Style Inventory (LSI) is an instrument designed by Kolb to help people on how to learn from experience, it is commercially available at (www.learningfromexperience.com). This instrument contains twelve items and participants have to rank-order four alternatives which correspond to the four learning styles [6].

3.1.4. Gregorc learning style model. The Gregorc Learning and Teaching Style Model was built based on phenomenological research. Gregorc argues that individuals have different mental qualities which focus and interact with the things that are more appropriate to them, and these qualities are related to perception, ordering, processing and relationships [6]. [14] defines learning style as "distinctive and observable behaviors that provide clues about the mediation abilities of individuals, how their minds relate to the world and, consequently, how they learn".

Only perception and ordering abilities have been presented by two orthogonal dimensions and combining adjacent abilities results in the following Learning Styles [15]:

- Abstract Sequential (AS): learners with this preference are able to get information from visual and verbal resources. They like the logical sequence of thinking and progress.

- Abstract Random (AR): This type of learners gets more from other's behaviour, so they like to work in groups. This learner likes to address information which is presented in an unstructured manner.

- Concrete Sequential (CS): People with this preference prefer concrete materials that are related to the real world presented in linear sequential order.

- Concrete Random (CR): This type of learner is characterized by a strong ability to investigate unstructured problems by using concept and experience. They seem to be active and intuitive learners.

The Gregorc Style Delineator (GSD) is a commercially available instrument at (www.gregorc.com) it provides metrics for an individual, in each of the four learning styles, namely AS, AR, CS and CR.

3.1.5. Dunn - Dunn learning style model. This model defines learning style as "the way in which individuals begin to concentrate on, process, internalize, retain new and difficult information" [16]. Dunn and Dunn claim that the learning style contains five dimensions, which are an Environmental dimension, an Emotional dimension, a Sociological dimension, a Physiological dimension and a Psychological dimension. These dimensions involve a number of supportive factors within each of them.

Dunn and Dunn designed the learning styles questionnaire as an instrument to determine the preferred learning style of children. However, this instrument was extended to produce a learning style inventory, which was presented in three versions. The adult's version is called Productivity Environmental Preference Survey (PEPS). [17].

(PEPS) is a commercially available questionnaire at (www.humanresources.com) for the purpose of helping students to know how they learn best, by providing metrics to student preferences in terms of Environmental, Emotional, Sociological, Physiological and Psychological dimensions. Each dimension includes a number of factors. For example, the environmental dimensions considered are noise, temperature and light.

\subsection{Implications and challenges of integrating learning style in the education process}

Over the last 50 years, many studies have been conducted in the field of education, the results of these studies revealed that students have different needs and abilities. Therefore, the researchers think that the consideration of student learning style is an influential factor in the success of education process, they also think that integrating the learning style in the education process might play an important role to make the learning faster and easier for learners. Moreover, many researchers including Felder and Silverman [12] argue that the educational environment must be designed in a manner which supports the students who have pure preferences such as pure visual students, otherwise they might experience many difficulties in their learning.

In order to consider the preferred learning style of students in the teaching process, a number of 
procedures can be conducted; firstly, the preferred learning style of students should be investigated. Secondly, the students should be made aware regarding their preferred learning style, and their strengths and weaknesses should be explained clearly to them. This knowledge helps them to improve, monitor and manage their learning $[2,18]$.

A more intensive way for considering the learning style in the education process is by matching the teaching style with the preferred learning style of students, this could be conducted through exposing the learners to educational activities and materials that correspond with their preferences and needs [2, 9, 10, 19-23].

Another point of concern deals with the huge number of different learning styles that might be taken into account, for example, according to FelderSilverman model the same class might include up to 625 styles [24]. Consequently, teachers might not be able to tackle each single learning style. Therefore, a number of adaptive educational systems have been developed to accommodate the individual differences even for even for a huge number of students with different learning styles, most of these systems use the learning style instruments (mentioned in Table 1) to achieve the matching process between the teaching and learning style $[2,23]$. In this research, we investigate the implications of using visual and active information as content for construction of the instruments of learning style and the extent to which this will influence the detecting the preferred learning style. In addition, we investigate the impact of using these forms of information on the time required for completing the instrument.

\subsection{Misuse of learning styles}

Although the research in the field of learning style started in the mid twentieth century, the researchers feel that many students and teachers lack an understanding of learning styles. For example, Dunn et al. [25] stated that great dangers might be faced as a result of learning style misuse, in this context some points need to be clarified:

- Dimensions of learning styles must not be treated as opposites because learners could be classified into both poles of a dimension at the same time. For example, a good number of students work very well both alone and in a team.

- Learning style is not a static behaviour. Therefore, learner tendencies might be changed by exposing the learner continually to an educational environment that matches their weaknesses.

- Student preferences in the same dimension are different. For example, Visual students could have a pure, moderate or mild tendency.

\section{Research question}

In this work, by comparing the preferred learning style of six students, and carrying out follow up interviews them, the researchers attempt to answer the following questions.

1. To what extent does using visual and active content in the instrument affect the measuring of preferred learning style?

2. What impact does the use of the visual and active content-based instrument have on the time taken to undertake the detection?

This research aims to be an important step in determining the most appropriate learning style instrument and to avert the potential problems arising from a miss-measurement of learning style.

In particular, this research aims to help us to understand the impact of content (forms of information) that could be used to build learning style instrument and improve its precision and efficiency.

\section{Methodology}

According to Cagiltay and Bichelmeyer [26], a phenomenon cannot be completely investigated by quantitative research alone. Therefore, in this study, qualitative research techniques are also used to answer the research questions. The preferred learning style of six students has been measured using two different instruments, whereby, the students underwent both a developed instrument which was enhanced by visual and active forms of information and a VARK questionnaire which depends only on the textual form of information. The results of both approaches were compared, and the researcher conducted six interviews with the participants about their preferred learning style and their opinion about the effect of using the visual and active content in the construction of learning style instruments.

\section{Participants}

The researchers conducted interviews with six participants from a school of Science and Technology at Nottingham Trent University. Table 2 shows participants' details.

Table 2. Participants description

\begin{tabular}{|c|c|c|}
\hline Coding name & Gender & Age \\
\hline P1 & Male & 24 \\
\hline P2 & Female & 24 \\
\hline P3 & Male & 27 \\
\hline P4 & Male & 26 \\
\hline
\end{tabular}




\begin{tabular}{|c|c|c|}
\hline P5 & Male & 25 \\
\hline P6 & Male & 25 \\
\hline
\end{tabular}

\section{Data collection}

The preferred learning style of participants have been measured twice by using two different learning style instruments, and then the participants have been interviewed. Audio records and field notes were used to collect data from each interview.

At the beginning of each interview, the researcher explained the purposes and aims of this work and each participant was made aware of key issues related to the concept of learning style as well as their right to withdraw from the study. The interviews were semi-structured, since the sessions of the interview were not restricted to specific questions, and the nature of the interview was determined by participant response.

\section{Developed instrument}

Visual and active forms of information such as graphs, figures and formulae were used to construct the developed instrument, which consists of sixteen items; each item has four alternative answers which correspond to the four learner types. These alternatives are given a priority level by the participants from (0 least important) to (3 most important) with the option of giving the same level of priority to more than one alternative. The score of each type is collected with the range being 0 to 48 . This range can be divided into three levels which are mild preference (from 1 to 16), moderate preference (from 17 to 32) and pure preference (from 33 to 48). Table 3 shows an example question from the developed instrument.

\subsection{Why the developed instrument is different?}

As mentioned above, the research on education has indicated that students have different learning styles $[1,27]$. In other words, they respond to the materials in different ways; for example, visual students respond strongly to the visual forms of information. Therefore, the question that needs to be asked is why the existing instruments are not provided in a visual and active way to correspond to the different types of learners [20]. This is both for the purpose of attracting and motivating the students to answer the questions and reduce the time needed to answer. This study aims to investigate the effect of enhancing the instruments by adding some new visual and active features.

The following points illustrate the differences between the developed and standard instruments by highlighting the advantages of developed instruments:

- The content of developed instrument: the content is presented in a different manner to correspond to the different types of learners. For example, visual resources like figures, graphs and charts are used to build the questions which measure visual learners. Table 3 illustrates some of this visual content.

- Mechanism of answering: respondents can answer by giving a priority level from 0 (least important) to 3 (most important) in the boxes for the respective choices, they can also give the same priority level for different choices. This mechanism to ensure that the learning preferences will not be treated as dichotomies (either/or options).

\section{Results}

\subsection{Preferred learning style of participants}

Table 4 shows the distribution of participant preferred learning styles in each dimension based on both a VARK questionnaire and developed instrument. $\mathrm{N}=6$.

By comparing the number of students in each dimension we can see that there is a notable difference between the results of two instruments, for example, based on the results of the developed instrument, all of the participants (6 students) have a pure visual preference, whereas the results of VARK questionnaire suggests that no participant has a pure visual preference. Another difference is the increase in the number of students who have moderate (read/write) preference, from one student according to VARK questionnaire to five students based on the developed instrument. On the other hand, the number of students who have moderate aural preference decreased from five students (based on the developed instrument) to only two students according to VARK questionnaire. These differences can be presented visually in Figure 1.

Although some researchers argue that 30 participants is the minimum acceptable sample size to ensure the normal distribution of data and conduct statistical analysis, others write that statistical analysis could be conducted with a much smaller number of participants [28, 29].

Accordingly, for more investigation, a Paired tTest was conducted to determine if there were any significant differences between the average of student learning styles before and after using visual and active content. 
Table 3. Sample from developed instrument

\begin{tabular}{|c|c|}
\hline \multicolumn{2}{|c|}{$\begin{array}{l}\text { Please write priority level from ( } 0 \text { least important) to ( } 3 \text { most important) in the } \\
\text { dashed boxes for the respective choices, you can give the same priority level for } \\
\text { different choices }\end{array}$} \\
\hline \multicolumn{2}{|l|}{ Q7: Which presentation style do you prefer? } \\
\hline $\begin{array}{l}\text { Pythagoras' theorem states that the square } \\
\text { of the hypotenuse (the side opposite the } \\
\text { right angle) is equal to the sum of the } \\
\text { squares of the other two sides. }\end{array}$ & $\begin{array}{l}a^{2}+b^{2}=c^{2} \\
c^{2}=a^{2}+b^{2} \\
c=\sqrt{ }(a 2+b 2)\end{array}$ \\
\hline $\begin{array}{l}\text { In right-angled triangles Square of the } \\
\text { Hypotenuse }(c) \text { equal the sum of the squares } \\
\text { of the other two sides } a, b \text {. } \\
\text { If } c^{2}=a^{2}+b^{2} \\
\text { Then } c=\ldots \ldots \ldots \ldots . . . . .\end{array}$ & $\begin{array}{l}\text { Pythagoras' theorem states that the square of } \\
\text { the hypotenuse (the side opposite the right } \\
\text { angle) is equal to the sum of the squares of the } \\
\text { other two sides. } \\
\text { So if other sides } a=3, b=4 \text { then Hypotenuse } \\
c^{2}=a^{2}+b^{2} \\
c 2=9+16=25 \text { then } c=\sqrt{25}=5\end{array}$ \\
\hline
\end{tabular}

Based on the results of the Paired t-Test, there were significant differences between the averages of student preferred learning styles within three preferences out of four, whereby the value of $p$ in active, visual and passive dimension is less than 0.5 .

- $\quad$ Read/Write style $(\mathrm{t}=-4.911, \mathrm{p}=0.004)$;

- Visual dimension ( $\mathrm{t}=-7.993, \mathrm{p}=0.0005)$;

- $\quad$ Kinaesthetic style $(\mathrm{t}=-3.095, \mathrm{p}=0.027)$.

The results also revealed that there were no significant differences between the averages of student preferred learning styles in terms of verbal style $(\mathrm{t}=-1.780, \mathrm{p}=0.135)$. This result may be interpreted by the fact that the both instruments (VARK and Developed) depended on the textual form of information to present the questions that related to this type of learners (Aural).

\subsection{Participant perception of learning style}

At the start of each interview, participants were made aware of their preferred learning style which was measured by the two instruments. The participants were asked about the importance of considering the individual differences among students in teaching methods. All of the participants indicated that the individual differences should be considered in teaching because one teaching method cannot fit all students:

"Teaching should always include everything; we cannot depend on only one method" (P5).

"Teachers should use different materials as much as they can because that will help students to keep the knowledge for a long time" (P4).

"Teachers should be considering individual differences between students, that will be very useful especially for students who have less concentration" (P6)

Table 4. Participants' preferred learning style

\begin{tabular}{|l|l|l|l|l|l|l|l|l|}
\hline \multirow{2}{*}{} & \multicolumn{2}{|c|}{ Visual } & \multicolumn{2}{|c|}{ Aural } & \multicolumn{2}{l|}{$\begin{array}{l}\text { Kinest- } \\
\text { hetic }\end{array}$} & \multicolumn{2}{|l|}{$\begin{array}{l}\text { Read / } \\
\text { Write }\end{array}$} \\
\cline { 2 - 8 } & V & D & V & D & V & D & V & D \\
\hline$\frac{D}{D}$ & 0 & 6 & 1 & 1 & 1 & 3 & 0 & 0 \\
\hline
\end{tabular}




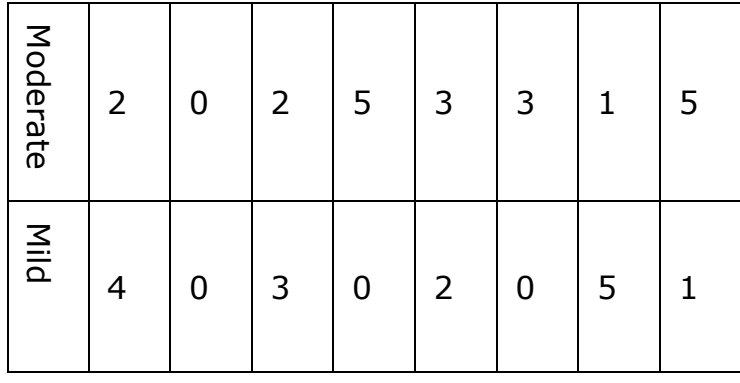

V - VARK Questionnaire.

D - Developed instrument.

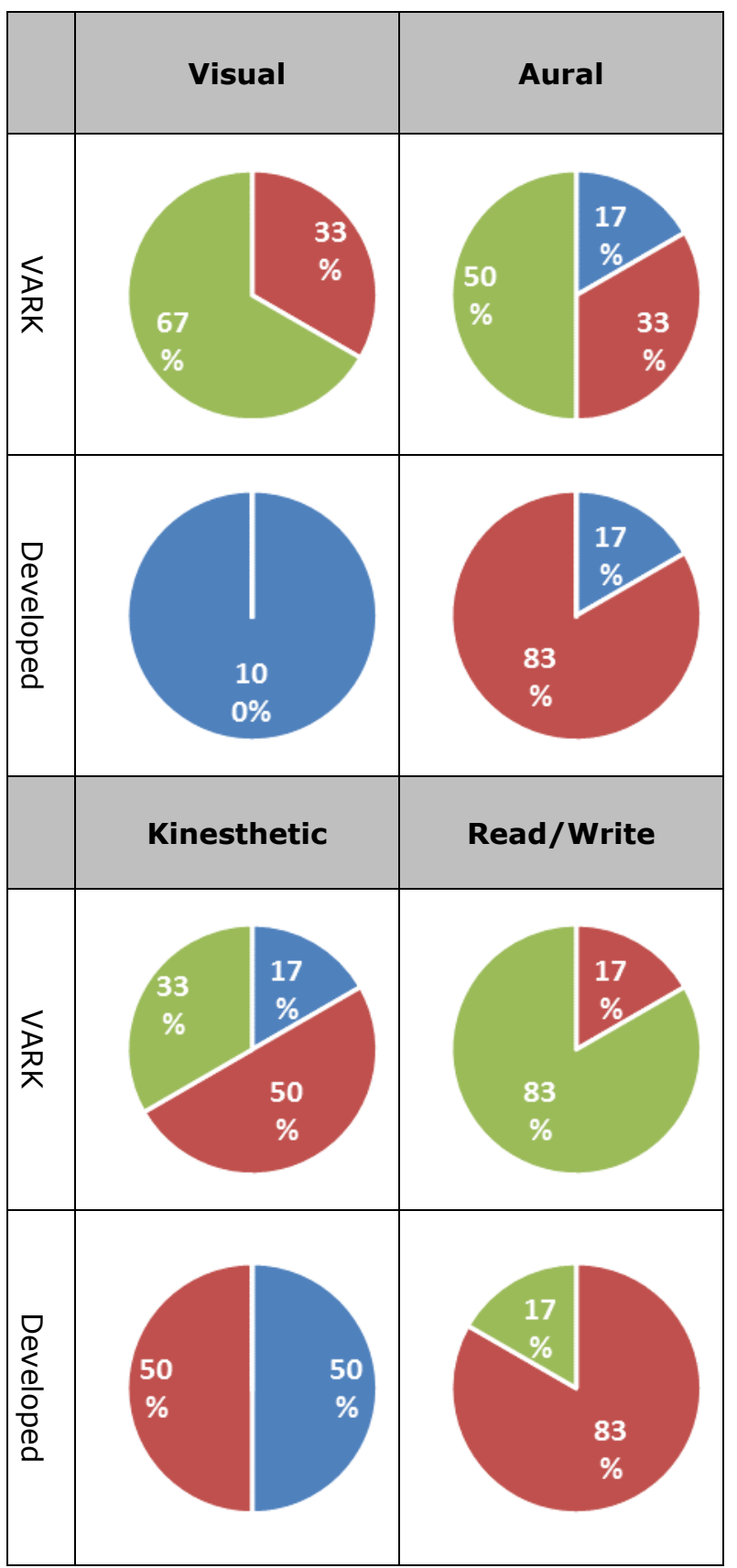

\begin{tabular}{|ll|}
$\square \quad$ Pure preference \\
$\square \quad$ Moderate preference \\
$\square \quad$ Mild preference \\
\hline
\end{tabular}

Figure 1. Preferred learning style of participants

\subsection{Impact of content on the answer of participants}

The majority of participants (five out of six) think that using visual and active content in the developed instrument affected their responses to the point where it altered the assessment of their preferred learning style:

"students understand the text differently" (P2).

"Using graphs rather than text makes the information easier to understand" (P1)

"These features will attract the whole class; it will also attract those students who are not more interested in learning" (P3).

(P1) "Using only text form, may get confused sometimes, it should be inclusive the both visual and verbal."

Only one participant (P5) thinks that the answer will not be affected except:

"There is a possibility if someone does not understand English very well. Obviously, for them, the answers will be affected because they may miss something when there is complete text" (P5).

\subsection{Impact of content on time}

Another issue that we have investigated in this work is the effect of using different forms of content in the instrument of learning style on the time taken to complete the instrument. The participants were asked whether they believe that the content of the instrument played any role to affect the time needed to complete the instrument. All of the participants stated that the visual and active content played a key role in reducing the time needed to finish the instrument:

(P1) "Defiantly, that is an effect, for example, if we don't know the mean formula we need to read and break down the text to extract the formula and that takes time and may get confused sometimes".

(P4) "The style of question presentation will affect the answer and the time needed for the answer, for example, providing students with the equation of Pythagoras easier and faster than 
providing them with a description of Pythagoras' theorem"

(P5) "I prefer both (visual and verbal forms) but when I see the things I can understand more quickly than reading ... the only difference is the complete text one takes the time to understand the question first of all, but as soon as I see a formula or graph I will get the idea. So the answer will not an affected but time will be affected".

\section{Discussion}

The results of this study provide new insights into the implications of using different forms of information on the efficiency and effectiveness of learning styles instruments, which are widely used in adaptive education systems.

In general, the results indicate that the use of different forms of content to build the learning style instruments, have a significant impact on the results of measurement the preferred learning style, and the time needed to complete the questionnaire.

The results showed that the number of students who classified as a "pure visual type" is increased significantly when they used the developed instrument, which contains visual forms of information. This result may be interpreted by the fact that visual type of learners responds strongly to the visual content such as (pictures, charts, figures ... etc.), and the VARK questionnaire does not contain any visual material.

In contrast, the number of "pure aural students" and "pure read/write students" have not seen any significant differences. This result may be explained by the fact that the both instruments used a textual information to present the questions that related to these types of learners (Aural, Read/Write).

The main implication of this study is that the result of measuring the preferred learning style could be changed according to the type of instruments' content. Therefore, it is critical to design our teaching strategies, especially adaptive education systems based on the outcomes of learning style instruments, which depend on textual information only to present its items.

\section{Limitations}

The main limitation of this research is the small number of participants. Especially as they are studying at the same course in the same university and only one participant (out of six) is female. Therefore, to generalize the results of this study, further research with a greater number of participants from different universities and courses is required.

\section{Conclusion}

Results of this study indicated that there is a need for more investigation in terms of the impact of instruments' content on the efficiency of measuring the preferred learning style of students. Since we know that these instruments have used by the most of adaptive educational systems for the purpose of student modelling and matching the teaching style with the preferred learning style of students [3]. Accordingly, it is important to investigate, to what extent these instruments are precise and effective before designing a teaching approach based on them.

\section{References}

[1] A. Franzoni-Velázquez, F. Cervantes-Pérez and S. Assar, "A Quantitative Analysis of Student Learning Styles and Teacher Teachings Strategies in a Mexican Higher Education Institution," Journal of Applied Research and Technology, vol. 10, pp. 289308, 2012.

[2] H. M. Truong, "Integrating learning styles and adaptive e-learning system: current developments, problems and opportunities," Comput. Hum. Behav., vol. 55, pp. 1185-1193, 2016.

[3] Ö Özyurt and H. Özyurt, "Learning style based individualized adaptive e-learning environments: Content analysis of the articles published from 2005 to 2014," Comput. Hum. Behav., vol. 52, pp. 349$358,2015$.

[4] A. L. Franzoni, S. Assar, B. Defude and J. Rojas, "Student learning styles adaptation method based on teaching strategies and electronic media," in Advanced Learning Technologies, 2008. ICALT'08. Eighth IEEE International Conference On, 2008, pp. 778-782.

[5] L. Thomas, M. Ratcliffe, J. Woodbury and E. Jarman, "Learning styles and performance in the introductory programming sequence," in ACM SIGCSE Bulletin, 2002, pp. 33-37.

[6] T. F. Hawk and A. J. Shah, "Using learning style instruments to enhance student learning," Decision Sciences Journal of Innovative Education, vol. 5, pp. 1-19, 2007.

[7] T. J. Sewall, "The Measurement of Learning Style: A Critique of Four Assessment Tools." 1986. [8] A. Sife, E. Lwoga and C. Sanga, "New technologies for teaching and learning: Challenges for higher learning institutions in developing countries," International Journal of Education and Development using ICT, vol. 3, 2007. 
[9] R. M. Felder and J. Spurlin, "Applications, reliability and validity of the index of learning styles," International Journal of Engineering Education, vol. 21, pp. 103-112, 2005.

[10] N. Othman and M. H. Amiruddin, "Different perspectives of learning styles from VARK model," Procedia-Social and Behavioral Sciences, vol. 7, pp. 652-660, 2010.

[11] N. D. Fleming, Teaching and Learning Styles: VARK Strategies. ND Fleming, 2006.

[12] R. M. Felder and L. K. Silverman, "Learning and teaching styles in engineering education," Engineering Education, vol. 78, pp. 674-681, 1988.

[13] D. A. Kolb, Experiential Learning: Experience as the Source of Learning and Development. FT Press, 2014.

[14] A. F. Gregorc, "Learning/teaching styles: Their nature and effects," Student Learning Styles: Diagnosing and Prescribing Programs, pp. 19-26, 1979.

[15] A. F. Gregorc and H. B. Ward, "A new definition for individual," Nassp Bulletin, vol. 61, pp. 20-26, 1977.

[16] R. Dunn, "Understanding the Dunn and Dunn learning styles model and the need for individual diagnosis and prescription," Reading, Writing, and Learning Disabilities, vol. 6, pp. 223-247, 1990.

[17] R. Riding and S. Rayner, Cognitive Styles and Learning Strategies: Understanding Style Differences in Learning and Behavior. Routledge, 2013.

[18] F. Coffield, D. Moseley, E. Hall and K. Ecclestone, "Should we be using learning styles? What research has to say to practice," 2004.

[19] Z. A. Akasah and M. Alias, "Emphasizing learning of the affective domain for the realization of the engineering learning outcomes," Cognition, vol. 7, pp. 9, 2010.

[20] N. Fleming and D. Baume, "Learning Styles Again: VARKing up the right tree!" Educational Developments, vol. 7, pp. 4, 2006.

[21] L. Herod, "Learning Styles \& Strategies," Adult Learning \& Literacy, pp. 310-800, 2004.

[22] M. T. Alshammari, "Adaptation Based On Learning Style And Knowledge Level In E-Learning Systems," 2016.
[23] N. Al-Jojo, "Teacher assisting and subject adaptive material system: an Arabic adaptive learning environment, Phd thesis," Teacher Assisting and Subject Adaptive Material System: An Arabic Adaptive Learning Environment, 2012.

[24] S. Graf, "Adaptivity in Learning Management Systems Focussing on Learning Styles," Adaptivity in Learning Management Systems Focussing on Learning Styles, 2007.

[25] R. Dunn, T. DeBello, P. Brennan, J. Krimsky and P. Murrain, "Learning style researchers define differences differently," Educational Leadership, vol. 38, pp. 372-375, 1981.

[26] K. Cagiltay and B. Bichelmeyer, "Differences in Learning Styles in Different Cultures: A Qualitative Study." 2000.

[27] A. M. Alzain, S. Clark and G. Ireson, "Libyan higher education system, challenges and achievements," in Engineering Education (ICEED), 2014 IEEE 6th Conference On, 2014, pp. 67-72.

[28] J. C. de Winter, "Using the Student's t-test with extremely small sample sizes," Practical Assessment, Research \& Evaluation, vol. 18, pp. 1-12, 2013.

[29] S. Janušonis, "Comparing two small samples with an unstable, treatment-independent baseline," J. Neurosci. Methods, vol. 179, pp. 173-178, 2009. 